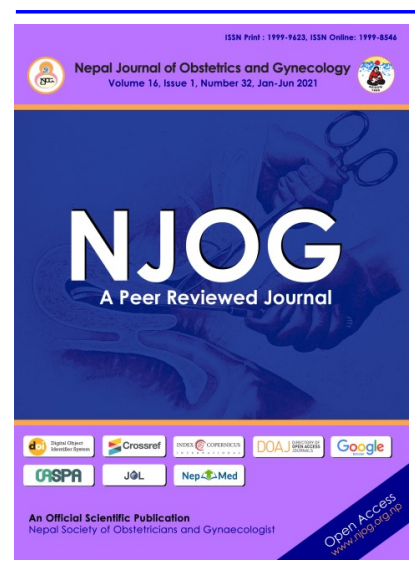

CORRESPONDENCE

Dr Benju Pandit

Department of OBGYN, Bhaktapur Hospital,

Nepal

Email:

mebenzu@gmail.com; Phone:+977-9840098660

Received: May 1, 2021

Accepted: May 20, 2021

\section{Citation:}

Pandit B. Choice of temporary contraception based on client's demographic status and parity. Nep J Obstet Gynecol. 2021;16(32):8587. DOI: https://

doi.org/10.3126/

njog.v16i1.37611

\title{
Choice of temporary contraception based on client's demographic status and parity
}

\author{
Benju Pandit \\ Department of OBGYN, Bhaktapur Hospital, Nepal
}

\section{ABSTRACT}

Aim: To analyze the demographic factors and parity in women influencing choice of contraceptive methods.

Methods: This is a hospital record based retrospective study at Bhaktapur hospital, a tertiary hospital in a span of 6 months from October 2020 to March 2021. Data were collected from medical record and descriptive analysis was done.

Results: There were 142 women taking contraceptive service in six months. Implant was the most commonly used method of contraception $(48 \%)$, followed by the IUCD (26\%), Injectable (16\%) and OCP (10\%). Age group of 2039 had more acceptance of contraception as compared to adolescent and women above 40 . More the parity more usage of long acting reversible contraception was found.

Conclusion: The most common contraceptive method used among women was implant. Client having two or more children are more to receive long acting contraception.

Keywords: contraception, demographic status, family planning

\section{INTRODUCTION}

Family Planning is one of the priority programs of Government of $\mathrm{Ne}$ pal, Ministry of Health. The modern contraceptive prevalence rate increased from $26 \%$ in 1996 to $43 \%$ in 2016. ${ }^{1}$ In Nepal, family planning services are offered in all district level hospitals, primary health care centers, health posts, urban health centers; $88 \%$ of the zonal and above hospitals of government and in $70 \%$ of the private hospitals. ${ }^{2}$ In government health system, currently, short acting reversible contraceptive methods (male condoms, oral pills and injectable) are provided on a regular basis through primary health care centers, health posts and primary health care outreach clinics. Long acting reversible contraceptive services such as IUCD and implants are available only at limited number of hospitals, PHC and Health posts where trained health care providers are available. ${ }^{2}$ The objective of this study is to understand the contraceptive users' profile in order to explore further area of research on contraceptive practices.

\section{METHODS}

This is a medical record based study at Bhaktapur Hospital over a period of 6 months from October 2020 to March 2021. Study variables were age, parity, education, religion and choice of contraception. Data were entered in MSExcel to generate tables and figures for the analysis. Descriptive analysis was performed.

\section{RESULTS}

There were 142 women who received contraception in six months. Majority of women (48\%) preferred Implant as their $1^{\text {st }}$ choice of contraception, followed by IUCD, injectable and OCP. [Figure-1]

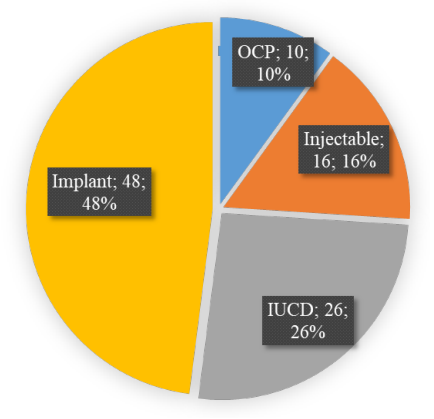

Figure-1: Choice of contraception 
Maximum number of clients $(46.5 \%)$ were from 25 to 35 years of age and $22.5 \%$ were 40 years and above. [Table-1]

Table-1: Age distribution ( $\mathrm{N}=142)$

\begin{tabular}{ccc}
\hline $\begin{array}{c}\text { Age group } \\
\text { (Years) }\end{array}$ & Frequency & $\%$ \\
\hline $15-19$ & 6 & 4.22 \\
$20-24$ & 18 & 12.67 \\
$25-29$ & 34 & 23.94 \\
$30-34$ & 32 & 22.53 \\
$35-39$ & 20 & 14.08 \\
$\geq 40$ & 32 & 22.53 \\
\hline
\end{tabular}

Majority of them (around 90\%) were literate and of Hindu family. [Table-2]

Table-2: Distribution by education and religion $(\mathrm{N}=142)$

\begin{tabular}{llcc}
\hline Variables & & $\mathrm{N}$ & $\%$ \\
\hline \multirow{2}{*}{ Education } & Illiterate & 14 & 9.86 \\
& Literate & 128 & 90.14 \\
\hline \multirow{4}{*}{ Religion } & Hindu & 126 & 88.73 \\
& Muslim & 4 & 2.81 \\
& Christian & 2 & 1.40 \\
& Buddhist & 10 & 7.04 \\
\hline
\end{tabular}

Maximum number of clients (45\%) had two children and multipara were only 5\%. [Table-3]

Table-3: Parity-wise distribution of clients $(\mathrm{N}=142)$

\begin{tabular}{ccc}
\hline Parity & $\mathrm{N}$ & $\%$ \\
\hline 1 & 33 & 23.23 \\
2 & 64 & 45.07 \\
3 & 37 & 26.05 \\
$\geq 4$ & 8 & 5.63 \\
\hline
\end{tabular}

\section{DISCUSSION}

Identification of women's choice of contraception is of importance for our better understanding of factors influencing women in their decision to start or stop using contraception.

A study done by USAID and Engender Health acceptors of each of the four methods in which acceptors of Norplant and IUCD are much more likely to reside in urban areas than those who use the Oral Contraceptive Pill (OCP) or injectable Depoprovera (Depo). This pattern may be due to more availability of Norplant and IUCD in urban health facilities. ${ }^{3}$ The result is similar to my study as implant users are more $(48 \%)$ followed by IUCD (26\%). However, Depo-provera is most favorable method followed by oral Pills in Nepal. ${ }^{4}$

Education helps to create awareness about the availability of various family planning methods. Howeve $r$, education was not important influencing factor for choice of contraception in this study. Similar findings were revealed by Mohanlal $\mathrm{P}$ et $\mathrm{al}^{5}$ and Donati et $\mathrm{al}^{6}$ for the acceptance of family planning methods.

In a study done by Iyer $\mathrm{S},{ }^{7}$ religion do play a role in different ethnic communities in India but it was like this in a study done by A.Srikanthan ${ }^{8}$ in Canada. This could be because of difference in literacy rate and awareness program in place. Nepal's contraceptive awareness program and service available free of cost by the government might have influenced the users' profile.

In my study, most women preferred Implant and IUCD as contraception. The use of contraception is more in women having two or more children and there was less acceptance of OCP or Depo as contraception as they might use permanent family method of contraception, long acting contraception or they might have completed family. This finding is similar to study done by Emuveyan EE et al, whose findings suggest the more the parity, less chance of using OCP or Depo.

In my study, women aged above 40 mostly prefer implant and IUCD as contraception. This finding is similar to study done by Crosignani et al, ${ }^{10}$ whose findings suggest women above 40 are less likely to go for OCP or depo as they are approaching menopause or have completed family or prefer permanent sterilisation. Similarly in my study, the adolescent group (15-19) are less involved as they might have inadequate knowledge about contraception .This finding is supported by study done by Blanc et $\mathrm{al}^{11}$ whose study suggests among adolescents there is shorter periods of consistent use with more contraceptive failure and more stopping for other reasons. This study is also similar to findings from NIDHS 2011, which suggested that younger women might be waiting for completion of their family. ${ }^{12}$ In my study, the age group between 20 and 24 mostly prefer Implant, followed by Depo. The age group between 25-29 also prefers implant as $1^{\text {st }}$ choice followed by IUCD, likewise in age group 30 to 39 , implant is $1^{\text {st }}$ preference followed by IUCD and Depo. As it may be influenced by counseling by health workers, husband's influence on choice of contraception and may be shifting of contraception from short acting to long acting. These findings are similar to study done by Joseph et $\mathrm{al}^{13}$ whose findings are that there was no significant association between women aged 20-29 years, 30-39 years and contraceptive use.

Because of retrospective in nature this study could not explore reason to choose contraceptive methods and their adherence. 


\section{CONCLUSIONS}

Majority of clients received implant followed by IUCD. It is likely that the pattern of contraception use among the population especially the educated ones may have begun to shift towards the implant and IUCD especially in clients with more than two children. Further studies in future needed to investigate satisfaction, continuation, shifting from one contraceptive measure to another and complications among users.

\section{REFERENCES}

1. Pant PD, Pandey JP, Bietsch K. Unmet Need for Family Planning and Fertility in Nepal: Levels, Trends, and Determinants. 2019. DHS Further Analysis Reports No. 119. Rockville, Maryland, USA.

2. MoH. Demographic and Health Survey 2011. Nepal: Population Division, Ministry of Health and Population; 2011. URL: https:// www.mohp.gov.np/eng/program/reproductivematernal-health/family-planning-programme

3. USAID and Engender Health. Contraceptive Use and Discontinuation Patterns in Nepal: Norplant, IUCD, Pill, and Injectables. 2003. [Cited 2015 Jan 1]. Available from hptt/ www.engenderhealth.org,

4. DoHS. Annual Report 2018/2019. Kathmandu: Ministry of Health and Population, Department of Health Services; 2019. URL: http:// dohs.gov.np/dohs-annual-report-fy-2076-77/

5. Mohanan P, Kamath A, Sajjan BS. Fertility pattern and family planning practices in a rural area in Dakshina Kannada. Indian J Com Med. 2003;28(1):15.
6. Donati S, Sharma N, Medda E, Grandolfo M. Family Planning Knowledge, Attitude and Practice (KAP) Survey in Manipur State. J Obstet Gynaecol India. 2003;53:485-90.

7. Iyer S. Religion and the decision to use contraception in India. J Sci Stud Relig. 2002;41 (4):711-22.

8. Srikanthan A, Reid RL. Religious and cultural influences on contraception. J Obstet Gynaecol Canada. 2008;30(2):129-37.

9. Emuveyan EE, Oshinyemi $\mathrm{H}$, Durojaiye $\mathrm{G}$, Dixon RA. Contraceptive choice in Lagos, Nigeria. West African J Med. 1990;9(2):129-34.

10. ESHRE Capri Workshop Group. Female contraception over 40. Hum Reprod Update. 2009;15(6):599-612.

11. Blanc AK, Tsui AO, Croft TN, Trevitt JL. Patterns and trends in adolescents' contraceptive use and discontinuation in developing countries and comparisons with adult women. Int Perspec Sexual Reprod Health. 2009:63-71.

12. MoHP, New ERA, and Macro International Inc: Nepal Demographic and Health Survey 2011. Kathmandu: Ministry of Health and Population [Nepal], New ERA, and Macro International Inc; 2012.

13. Lasong J, Zhang Y, Gebremedhin SA, Opoku S, Abaidoo CS, Mkandawire T, et al. Determinants of modern contraceptive use among married women of reproductive age: a crosssectional study in rural Zambia. BMJ open. 2020;10(3):e030980. 